\title{
OTOACOUSTIC EMISSION MEASUREMENTS IN EVALUATION OF THE IMMEDIATE EFFECT OF VENTILATION TUBE INSERTION IN CHILDREN
}

\author{
STIJN C. TILANUS, MD \\ DESIREE VAN STENIS, MD \\ AD F. M. SNIK, PHD \\ NIJMEGEN, TTIE NETHERLANDS
}

\begin{abstract}
It is generally acknowledged that hearing assessment is needed before and after possible surgical intervention in children with otitis media with effusion. The conventional method in young children is visual reinforcement audiometry, which requires much time and cooperation from the child. The assessment of otoacoustic emissions may be an alternative, as it is proven to be rapid, easy, and objective as a screening procedure. We studied the applicability of click-evoked otoacoustic emissions to assess hearing acuity in children with otitis media with effusion who were scheduled for ventilation tube insertion. To avoid cooperation problems, the measurements were performed in the operating room immediately before and after ventilation tube insertion with the child under general anesthesia. None of the ears tested $(n=29)$ showed any increase in otoacoustic emissions when preoperative and postoperative levels were compared. At follow-up visits, however, $80 \%$ of the tested ears did. The acute outcome may be best explained by assuming that the surgical manipulations themselves were responsible, either through their fatiguing effects on the outer hair cells caused by the suctioning noise, or through their mechanical effects on the middle ear processes that govern reverse transmission from the cochlea to the outer ear canal. We conclude that it is not worthwhile to measure otoacoustic cmissions directly after ventilation tube insertion to assess the effect on hearing acuity, although they may be valuable in the outpatient setting.
\end{abstract}

KEY WORDS - hearing assessment, otitis media with effusion, otoacoustic emissions, ventilation tube.

\section{INTRODUCTION}

Since the discovery of otoacoustic emissions (OAEs) by Kemp in $1978,{ }^{1}$ several studies have been published on clinical applications in children. ${ }^{2-6}$ Especially in neonates, the OAE test is today acknowledged as an easy-to-use, quick, and reliable screening test. Measurement of OAEs has also been applied to evaluate the effect of ventilation tube insertion on the hearing acuity of children with otitis media with effusion (OME). 4,6 The conventional way of evaluating hearing acuity is to determine the hearing thresholds. This is time-consuming, especially in young children in whom visual reinforcement techniques have to be applied. Nevertheless, it is of the utmost importance to obtain at least an indication of the hearing acuity before and after ventilation tube insertion. In this respect, measurement of the OAEs seems to be an alternative, although cooperation is a problem, especially in young children. The child has to accept the probe in the ear and sit quietly for some time. This procedure often causes problems in young children in the age range most sensitive to OME. Therefore, it seems more practical to perform the $\mathrm{OAE}$ measurements immediately after ventilation tube insertion, while the child is still anesthetized. This approach is supported by the fact that an instant improvement in hearing is often reported after the surgical procedure. The aim of this study was to evaluate the applicability of transient-evoked oto- acoustic emissions (TEOAEs) to assess hearing acuity immediately after ventilation tube insertion while the child was still under anesthesia.

\section{MATERIAL AND METHODS}

Subjects. The test group comprised 32 children under general anesthesia in whom OAE measurements were performed immediately before and after ventilation tube insertion in the operating room; the ages of the children varied from 1 to 14 years (mean, 5.1 years). They were scheduled for ventilation tube insertion because the standard medical intervention for OME at our clinic, which consists of decongestant nose drops or mucolytics, had not been effective. In general, when middle ear effusion and hearing loss still persist after 6 to 8 weeks, ventilation tubes are placed.

The OAE measurements obtained in the operating room in 8 of the 32 children were incomplete for several reasons: insufficient seal of the probe, a high noise level from loud breathing sounds, or logistic problems. In the operating room, only two attempts were made to fit the probe properly. If these were unsuccessful, the measurement was stopped. In 19 of the remaining 24 children, only the results of one ear were complete because a ventilation tube had been placed in one ear only or one of the TEOAE measurements was not obtained because of logistic problems

\footnotetext{
From the Department of Otorhinolaryngology, Nijmegen University Hospital, Nijmegen, the Netherlands.
} 
TABLE 1. "INPUT" CHARACTERISTICS OF TEOAE MEASUREMENTS

\begin{tabular}{|c|c|c|c|c|}
\hline & \multicolumn{2}{|c|}{ Test Group } & \multicolumn{2}{|c|}{ Control Groups } \\
\hline & Preop & Postop & $O M E$ & $V T$ \\
\hline No. of childre & 24 & 24 & 20 & 15 \\
\hline $\begin{array}{l}\text { Stimulus } \\
\text { level } \\
\text { (dB SPL) }\end{array}$ & $86.0 \pm 2.3$ & $87.6 \pm 2.5$ & $83.9 \pm 4.0$ & $85.3 \pm 3.5$ \\
\hline $\begin{array}{l}\text { Stimulus } \\
\text { stability } \\
(\%)\end{array}$ & $90.5 \pm 5.9$ & $90.9 \pm 4.9$ & $93.5 \pm 4.4$ & $92.6 \pm 5.3$ \\
\hline $\begin{array}{l}\text { Noise } \\
\text { level } \\
\text { (dB SPL) }\end{array}$ & $39.5 \pm 2.9$ & $40.2 \pm 3.8$ & $40.1 \pm 4.3$ & $38.1 \pm 3.5$ \\
\hline $\begin{array}{l}\text { Data are mea } \\
\text { TEOAE - tr } \\
\text { ately before } \\
\text { ventilation tu } \\
\text { effusion, VT. } \\
\text { pressure leve }\end{array}$ & $\begin{array}{l}\text { I SD. } \\
\text { ansient-evoke } \\
\text { entilation tul } \\
\text { be insertion, } \\
\text { - children w }\end{array}$ & $\begin{array}{l}\text { otoacoustic } \\
\text { e insertion, p } \\
\text { oMe - chilc } \\
\text { th ventilation }\end{array}$ & $\begin{array}{l}\text { mission, prea } \\
\text { stop - imn } \\
\text { ren with otit } \\
\text { ubes in situ, }\end{array}$ & $\begin{array}{l}\text {-immedi- } \\
\text { diately after } \\
\text { media with } \\
\text { PL - sound }\end{array}$ \\
\hline
\end{tabular}

or problems with the equipment. The results of 29 test ears were available for analysis.

The average hearing loss at $0.5,1,2$, and $4 \mathrm{kHz}$ (pure tone average [PTA]) was obtained an average of 4 weeks before the surgical procedure and varied from 15 to $47 \mathrm{~dB}$ hearing level (HL; mean, $31 \mathrm{~dB}$ HL). In several of the children, TEOAEs were also recorded during a regular outpatient visit before and/ or after the surgical procedure.

For comparison, OAE measurements were performed on two control groups: one group comprised children with normal hearing and ventilation tubes in situ (15 children, 23 ears); the other group comprised children with otoscopically verified OME (20 children, 33 ears). The children with ventilation tubes in situ had thresholds of $20 \mathrm{~dB} \mathrm{HL}$ or better. Their ages ranged from 1 to 10 years (mean, 5.0 years). The PTAs of the children with otoscopically verified OME ranged from 7 to $36 \mathrm{~dB}$ HL. Their ages varied from 3 to 12 years (mean, 5.4 years).

To exclude the results of children with sensorineural hearing loss, both in the test and control groups, we included only the results of the children with normal hearing (hearing thresholds of $20 \mathrm{~dB} \mathrm{HL}$ or better) at the time of testing or, in the group with OME, those with normal hearing at a date no more than 1 year prior to the testing or after ventilation tube insertion.

Procedure. Click-evoked OAEs were obtained with the ILO88 system (Otodynamics, Ltd), developed by Kemp et al.$^{2,8}$ The B-type probe was used and special care was taken to obtain a good seal of the probe in the ear canal. ${ }^{8}$ To save time in the operating room, the so-called "QuickScreen" mode with a time window from 5 to 12 milliseconds was used. 2 The initial measurement was performed after cleaning the ear canal, if necessary, just before myringotomy. After myringotomy, before the ventilation tube was inserted, as much effusion as possible was suctioned away. After the ventilation tube was in place, the postinsertion measurement was performed.

The anesthetic consisted of a gas mixture of nitrous oxide, oxygen, and halothane (1\% to $3 \%$ ). The measurements in the control subjects were taken in a quiet room (ambient noise level, $40 \mathrm{~A}$-weighted decibels) with the child lying comfortably on a bed. Most of the younger children were tested sitting on their parent's lap.

All the measurements were performed by the same audiologist. The TEOAE plots were judged for the presence or absence of an OAE independently by two experienced interpreters. Their judgments were based on the stimulus parameter values, visual inspection of the waveforms of the stimulus and OAE, and their spectra. If one of the interpreters was not sure about the presence or absence of an OAE, or if they disagreed, the OAE was scored as "doubtful." Additionally, comparisons were made between the test children and the control groups regarding the overall reproducibility, the level and stability of the stimulus, and the noise level taken from the overview of the results presented by the ILO88 software. ${ }^{2,8}$

Audiometry was performed in a double-walled sound-treated room with standard procedures and equipment (Interacoustics AC-5 audiometer with TDH-39P headphones, calibrated according to ISO 389). Hearing thresholds from 0.5 to $4 \mathrm{kHz}$ were available for all the children. For most of the children under 3 years of age, free-field visual reinforcement audiometry was used, with warble tones generated by the same audiometer. The free-field setup was calibrated according to Dirks and Morgan. ${ }^{9}$ In most of the children up to approximately 6 years of age, only unmasked thresholds were obtained.

\section{RESULTS}

In Table 1, the average stimulation level, stability of the stimulus, and noise level are presented for the test children and control groups. Only minor differences can be seen between the values obtained in the operating room (test children's values) and those obtained at the outpatient clinic (control group's values). Therefore, the measurement conditions in the operating room were acceptable. The stimulus level in the operating room was found to be higher 
TABLE 2. PRESENCE AND REPRODUCIBILITY OF OTOACOUSTIC EMISSIONS

\begin{tabular}{lrrrrr}
\hline \hline & \multicolumn{2}{c}{ Test Group } & \multicolumn{2}{c}{ Control Groups } \\
\cline { 2 - 3 } \cline { 5 - 6 } & Preop & Postop & & OME & $V T$ \\
\hline OAE present (\%) & 34 & 20 & 28 & 65 \\
OAE doubtful (\%) & 0 & 8 & 13 & 13 \\
$\begin{array}{l}\text { OAE absent (\%) } \\
\text { Reproducibility }\end{array}$ & 66 & 72 & 59 & 22 \\
$\begin{array}{l}\text { Percent with more } \\
\text { than 60\% }\end{array}$ & 29 & 4 & 12 & 57 \\
$\begin{array}{l}\text { Percent with } \\
\text { 40\% to 60\% }\end{array}$ & 8 & 20 & 12 & 13 \\
$\begin{array}{l}\text { Percent with less } \\
\text { than 40\% }\end{array}$ & 63 & 76 & 76 & 30 \\
$\begin{array}{l}\text { Preop - immediately before ventilation tube insertion, postop - } \\
\text { immediately after ventilation tube insertion, OME - children with } \\
\text { otitis media with effusion, VT- children with ventilation tubes in situ, } \\
\text { OAE - otoacoustic emission. }\end{array}$ & & & \\
\hline
\end{tabular}

than at the outpatient clinic, which may be caused by deeper probe insertion in the operating room.

During the surgical procedure, minimal effusion was found in 9 ears. Apparently, the OME had diminished between the last otolaryngological visit and the surgical procedure. Nevertheless, ventilation tubes were inserted because of the history of recurrent OME. In 7 of these 9 ears (78\%) an obvious OAE was found before ventilation tube insertion. Effusion was present in all of the other ears. In 3 of these ears $(15 \%)$, an $\mathrm{OAE}$ was found before ventilation tube insertion.

The occurrence and response reproducibility of the TEOAEs obtained before and after ventilation tube insertion are presented in Table 2. For comparison, the results of the control groups are also presented. Table 2 shows that immediately after insertion the occurrence of OAEs decreased markedly. This also held true for the reproducibility of the response, which is presented in Table 2 subdivided into three classes. In all 10 ears in which an $\mathrm{OAE}$ was found immediately before ventilation tube insertion, the reproducibility deteriorated after insertion by an average of $42 \%$ (range, $21 \%$ to $76 \%$ ). At follow-up visits at the outpatient clinic, TEOAE measurements were performed on 9 of the 24 test children; in all cases, open ventilation tubes were found and an obvious OAE was present in 12 of the 15 ears tested (80\%).

\section{DISCUSSION}

The results of the OAE measurements in the control groups showed that it is difficult to record OAEs in the presence of $O M E$; with ventilation tubes in situ, OAEs were found in the majority of children. This finding is in accordance with those of other studies. 4,6
The results of the measurements taken in the operating room showed that immediately after ventilation tube insertion, no improvement in hearing acuity was documented in any of the children with OAE measurements. Moreover, in most of the children, no $\mathrm{OAE}$ at all was found after the insertion of ventilation tubes. This is surprising, because OAEs were found in the majority of children with ventilation tubes in situ tested at the outpatient clinic. This also proved to be the case for the test children who were tested later at the outpatient clinic. It may be argued that there was still some effusion present in the middle ear after the surgical procedures, which diminished the mobility of the ossicular chain and caused hearing loss. However, this explanation is not valid for the 9 ears in which no or hardly any effusion was found. Furthermore, if an OAE was found before insertion, it became considerably poorer or disappeared after ventilation tube insertion. Therefore, other unfavorable factors induced by the treatment itself must play apart. The measurement conditions (personnel, equipment, posture of the child) are not a likely cause, because they did not change. It is also unlikely that the anesthetic had a direct effect on the TEOAE, because it has been reported that electrocochleography, which also quantifies inner ear activity, is not seriously influenced by anesthesia. ${ }^{10} \mathrm{~A}$ secondary effect of the anesthetic gas, namely, middle ear dysfunction owing to increased middle ear pressure by diffusion of the anesthetic gas into the middle ear, 11 can also be ruled out to explain the poor postinsertion $\mathrm{OAE}$ results, because the ventilation tube prevents any change in middle ear pressure.

A more probable factor to explain the poor postinsertion OAEs is a temporary threshold shift owing to the high noise levels caused by suctioning wax out of the ear canal and/or effusion from the middle car. ${ }^{12}$ Furthermore, temporary cochlear dysfunction may have also occurred as a result of the relatively strong displacement of the eardrum and adjacent middle and inner ear when the ventilation tube was placed; the mechanical waves in the cochlea may have overloaded the transduction mechanisms of the hair cells. Reversible damage to the middle ear structures, which diminished the emissions from the cochlea to the ear canal, may have also played a part.

The present setup does not allow us to explain the poor postinsertion OAEs in any more detail, but we can draw the clinically relevant conclusion that it is not worthwhile to perform TEAOE measurements in the operating room directly after ventilation tube insertion to assess the effect on hearing acuity. Nonetheless, OAE measurements may be helpful in the outpatient setting. 


\section{REFERENCES}

1. Kemp DT. Stimulated acoustic emissions from within the human auditory system. J Acoust Soc Am 1978;64:1386-91.

2. KempDT, Ryan S. The use of transient evoked otoacoustic emissions in neonatal hearing screening programs. Semin Hear 1993;14:30-44.

3. Bonfils P, Uziel A, Pujol R. Screening for auditory dysfunction in infants by evoked oto-acoustic emissions. Arch Otolaryngol Head Neck Surg 1988; 114:887-90.

4. Prieve BA. Otoacoustic emissions in infants and children: basic characteristics and clinical application. Semin Hear 1992; $13: 37-52$.

5. White KR, Vohr BR, Behrens TR. Universal newbom hearing screening using transient evoked otoacoustic emissions. Results of the Rhode Island Hearing Assessment Project. Semin Hear 1993;14:18-29.

6. Owens JJ, McCoy MJ, Lonsbury-Martin BL, Martin GK. Otoacoustic emissions in children with normal ears, middle ear dysfunction and ventilation tubes. Am J Otol 1993;14:34-40.

7. Zielhuis GA, Rach GH, Van den Bosch A, Van den Broek $P$. The prevalence of otitis media with effusion: a critical review of the literature. Clin Otolaryngol 1990;15:283-8.

8. Kemp DT, Ryan S, Bray P. A guide to the effective use of otoacoustic emissions. Ear Hear 1990;11:93-105.

9. Dirks DD, Morgan DE. Effect of loudspeaker position on differences between earphone and free-field thresholds. J Speech Hear Disord 1979;17:549-68.

10. Hall JW. Handbook of auditory evoked responses. Boston, Mass: Allyn and Bacon, 1992.

11. Hauser R, Probst R, Harris FP, Frei F. Influence of general anesthesia on transiently evoked otoacoustic emissions in humans. Ann Otol Rhinol Laryngol 1992;101:994-9.

12. Wetmore RF, Henry WJ, Konkle DF. Acoustical factors of noise created by suctioning middle car fluid. Arch Otolaryngol Head Neck Surg 1993;119:762-6.

\section{TH INTERNATIONAL PAPILLOMAVIRUS CONFERENCE}

The 14th International Papillomavirus Conference will be held July 23-28, 1995, in Quebec City, Canada. For information, please contact the Office of Continuing Medical Education, Faculty of Medicine, Room 1214, Laval University, Quebec G1K 7P4, Canada; telephone (418) 656-5958; fax (418) 656-2465; Internet ipc@fmed.ulaval.ca.

The Thirteenth International Course in Functional Corrective Nasal Surgery will be held June 25-30, 1995, in Utrecht, the Netherlands. For more information, contact Prof Dr E. H. Huizing, Dept of ORL, University Hospital Utrecht, PO Box 85500, 3508 GA Utrecht, the Netherlands; telephone 32-30-506645; fax 32-30-541922. 